or Corunna, called anciently Portus Brigantinus, in Gallicia." According to this the Briges would be the common ancestors of the Britons of England, France, and Spain, and the similarity of the names in these countries could be accounted for.

A. R. H.

\section{Faunas of Oceanic Islands}

In NATURE, of February I6, I observe the reviewer of Mr. Godman's "Natural History of the Azores," makes the following statement:- "Mr. Godman appears to be the first who has, after a personal exploration of one of these oceanic groups, endeavoured to collect all that is known of its natural productions." Now, it is not with the intention of detracting from the merits of $\mathrm{Mr}$. Godman's work, but merely to re'resh the nemory of your reviewer, that I beg to state, that I published in 1859 a smal volume entitled "The Naturalist in Bermuda," which contained all that was known of the natural productions of those islands at that date. It was by no means a complete essay, but as stated in the preface "merely a prelude to a more complete publication on the same subject, which anticipated work, the result cf several visits to the group, I hope to present to public notice shortly.

Institute of Natural Science, Halifax, Nova Scotia

Influence of Barometric Pressure on Ocean Currents

In the recent discussions on the influence of barometric pressure upon ocean currents, I have not seen any allusion to the observations that have been made upon the effect of variations of barometric pressure upon the sea-level. In a memoir by $M$. Ch. Aimé, "Sur les variations de niveau de la Mediterranée," in the Annales de Chimie, tome xii., 1844, it is stated that a fall in the barometer is pretty uniformly accompanied by a rise in the sea-level to about thirteen times its amount. The Report of the British Association for 1841 contains a letter from my old friend, Mr. T. G. Bunt, of Bristol, stating that his observations upon the tide-gange under his charge led him to conclude that a fall of one inch in the mercurial column was accompanied by an average rise of about $13 \frac{1}{2}$ inches in the high-water level. And the same industrious and careful observer, in a recent "Discussion of Tide Observations at Bristol" in the Philosophical Transactions for 1867 , gives as the mean result of twenty-one years' examination of this point, " 12.772 inches of tide to one inch of mercury." I referred to Mr. Bunt's observations in a discussion at the Geological Society (March 6, 1867) on a paper by the Earl of Selkirk "On some sea-water-level marks on the coast of Sweden," pointing out that some of the discrepancies in the observations as to the sea-level of the Baltic might be attributed without improbability to variations in barometric pressure. I have since learned from Admiral Key, who served in the Baltic fleet during the Russian war, that he had been led by his own observations to a like conclusion. And I find it stated in the description of the Baltic Sea, in the English Cyclorædia, that its level is sometimes observed to rise, and to remain thus elevated for a time without any obvious cause, two or three feet, of which pher:omenon the explanation is probably the same.

I am sorry to find that I have not succeeded in convincing $\mathrm{Mr}$. Laughton of the existence of a regular undercurrent in the Strait of Gibraltar. If he will take the trouble of carefully perusing the detailed report which I have presented to the Royal Society, he will find that he is quite in error in stating that $I$ rest my affirmation upon "one observation after several attempts made in vain." All our observations, when rightly interpreted, tended to the same conclusion. The reduction of the boat's drift almost to nothing, in the first set of experiments, when it lay in a surface-current running nearly three miles an hour, with a breeze setting in the same direction, was just as conclusive evidence that a reverse current must have been acting on the current-drag bi low, as was the reversal of the boat's drift in the subsequent expe-

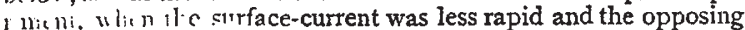
irece din inislecl its acticn on the boat. And our observations

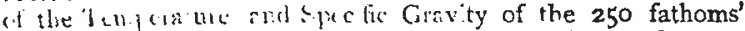
stratim necst un misialically indicatcd cn lolb occasions its Meditcranean dorivalis $n$.

I should like $10 \mathrm{kn} \times \mathrm{w}$ wat is the precise minimum of movement which is lield by Physical Geographers to constitute a current. There si enis to me a great deal of confusion upon this point. The cxistence of an underfow of polar water towards the Equator cambot now be a matter of question. Commander Chimn o bas recently obtained with the Miller-Casella thermo- meters a temperature of $33 \frac{1}{2}^{\circ}$ at a depth of 2,306 fathoms nearly under the equator. What is the rate of this movement is a point as yet undetermined. But the rate of the northerly fiow of warm surface-water between Scandinavia andinceland, which is usually attributed to the Gulf Stream, but which I regard as the complement of the southward flow of deep polar water in a vertical oceanic circulation, is estimated by Admiral Irminger at from $I_{2}^{2}$ to $2_{2}^{\top}$ miles per day. Is this, in the language of physical geography, a current?

University of London, April ro

The "Times" Review of Darwin's "Descent of Man"

THE British public are deeply indebted to the Times Reviewer for his very comforting and reassuring remarks on Mr. Darwin's "Descent of Man," in which he has so well exposed the " "utterly unsupported hypotheses," the "unsubstantial presump. tions," the "cursory investigations," of that "reckless" and "unscientific" writer. It is a great satisfaction to find that Mr. Darwin's odious conclusion that the genealogy of the Talbots, and the Howards, and the Percys must be traced back beyond the Conqueror to an Anthropomorphous Ape, and beyond the ape to an Acephalous Mollusk, rests on no logical foundation whatever. The Reviewer well suggests that anything so odious in idea, so immoral in its apparent tendency, and so different from what we have been accustomed to believe, cannot possibly be true. One is so glad indeed to be free once and for ever from the mischievous influence of such " unpractical," "disintegrating speculations," that it seems worth while trying, if space can be found for the experiment, to elicit from the good nature of the Reviewer, or of those who think with him, a little clearer expla. nation here and there, before the subject is finally consigned to a well-merited oblivion.

Mr. Darwin is invited in one passage, "if he wishes to corroborate his hypothesis, to commence by experimenting on some superior kind of Ascidian, and see whether, by patient selection, he can induce any of them to split themselves in half, and aban. don their permanent support for a vagrant oceanic existence." Now, it is a fact that among Corals or Polypes, which are not far removed from Ascidians, these interesting experiments are actually exhibited ; for the cæspitose Corals, by what is called fissiparity, do split themselves in half, thus forming two complete individuals where only one grew before, and the Corals of the genus Fungia are fixed when very young, but subsequently break their pedicels and become free. The whole group of Zoophytes, recent and fossil, connects together marvellously different forms by an almost infinite series of wonderfully minute links. The study of such a group is therefore no doubt dangerous, if not decidedly pernicious, as tending to gloss over "the enormous and painful improbability" of Mr. Darwin's speculations. For if upon examination it seemed likely, or almost certain, that different genera of Polypes were connected with one another by descent, some rash enthusiast might think a similar conclusion not impossible in the order Primates. Fortunately, one is estopped from suggesting that in fact some genera of Polypes may be connected by descent, for fear of incurring the sharp reproach to which Mr. Darwin has so frequently laid himself open, of "conjugating the potential mood." Hitherto in most departments of thought and inquiry, probable evidence has been allowed to count for something, and most men are content to believe themselves to be the sons of their reputed fathers upon a mixture of evidence and authority, which, by the very nature of the case, can never rise to absolute demonstration. The Reviewer has done good service to society by showing the untrustworthy character of the foundation on which all our genealogies are built. It would be well in future if some auxiliary verb, expressive of doubt and uncertainty, cculd be combined with our patronymics.

Mr. Darwin, it appears, has " a facile method of observing superficial resemblances." For instance he surprises the apprehension of the vulgar by exhibiting the curious likeness between the embryos of a man and a dog. As every one of course knows how he looked when he was still in his mother's womb and less than an inch long, that stage in a man's career when he is only too like an emhryo nuppy, might have been shrouded under a delicate reserve. If, in place of this absurd "superficial resemblance," Mr. Larwin could have pointed out similarities between man and the luner animals in 1 tgard to minute structures of bone ar:d muscle, or in the organs of sense or speech, his argument might lave been detmed a little more scientific. 